\title{
Budgets of rotational and divergent kinetic energy in the warm-sector torrential rains over South China: a case study
}

\author{
Shui-Xin Zhong ${ }^{1} \mathbb{D} \cdot$ Wei-Guang Meng ${ }^{1} \cdot$ Fu-You Tian ${ }^{2}$
}

Received: 5 July 2020 / Accepted: 17 January 2021 / Published online: 5 February 2021

(c) The Author(s) 2021

\begin{abstract}
The contributions of divergent and rotational wind components to the kinetic energy budget during a record-breaking rainstorm on 7 May 2017 over South China are examined. This warm-sector extreme precipitation caused historical maximum of $382.6 \mathrm{~mm}$ accumulated rainfall in $3 \mathrm{~h}$ over the Pearl River Delta (PRD) regions in South China. Results show that there was a high low-level southerly wind-speed tongue stretching into the PRD regions from the northeast of the South China Sea (SCS) during this extreme precipitation. The velocity potential exhibited a low-value center as well as a low-level divergencecenter over the SCS. The rotational components of the kinetic energy (KR)-related terms were the main contribution-terms of the kinetic energy budget. The main contribution-terms of KR and the divergent component of kinetic energy (KD) were the barotropical and baroclinic processes-related terms due to cross-contour flow and the vertical flux divergence.
\end{abstract}

\section{Introduction}

Synoptic-scale momentum transport plays an important role during the evolutions of atmospheric circulations and climate systems. It could exert strong impacts on the formation of the convective systems (e.g., strong low-level convergence and upper-level divergence in the mesoscale systems, Maddox et al. 1981). Kinetic energy analyses are recognized as effective methods to diagnose the source of momentum transformations and transfers in the convective environment (Fuelberg and Buechler 1989; Li 2007; Jin et al. 2020).

It was found that areas of the convections appeared to be formed where strong transfers of kinetic energy occurred (Buechler and Fuelberg 1986; Zhong 2011; Wang et al. 2016). In particular, the divergent component of kinetic energy (KD) was crucial to the total energy balance and the occurrence of the convections (e.g., horizontal flux

Responsible Editor: Silvia Trini Castelli.

Shui-Xin Zhong

zhongshuixin@126.com

1 Guangdong Province Key Laboratory of Regional Numerical Weather Prediction, Institute of Tropical and Marine Meteorology, China Meteorological Administration (CMA), Guangzhou 510080, China

2 National Meteorological Center, CMA, Beijing 100081, China divergence of kinetic energy, Fuelberg and Browning 1983), as well as the most important energy source of rotational component of kinetic energy (KR). The release of the eddy available potential energy enhanced $\mathrm{KD}$ and its conversion from KD to KR further enhanced the monsoon circulation (Krishnamurti and Ramanathan 1982). Although the magnitude of KD was small, it played an important role in kinetic energy budget. It was found that the horizontal convergent flux of KD in baroclinic process was one of the main energy sources of KR (Zhong 2011).

In the low level of troposphere, the potential energy triggered KD through the cross-contour divergent winds and then converted into KR (Chen and Chen 2002). Numerical simulations showed that KD dominated in the lower stratosphere while KR prevailed in the upper troposphere (Waite and Snyder 2009). The proportion of KD to kinetic energy could reach $70 \%$ near the surface and in the upper troposphere toward $100 \mathrm{hPa}$ (Blažica et al. 2013). However, for some intense convective activity and subsynoptic-scale low-level jets (LLJs) events, KR dominated the total kinetic energy (Fuelberg and Browning 1983; Chen and Chen 2002). It was found that the formation of the lower and middle tropospheric cyclones featured an enhancement of KR, whereas the formation of the upper tropospheric cyclone featured a decrease of KR (Li et al. 2019).

Warm sector torrential rain (WSTR) is one of the most influential weather systems during the flood seasons over South China (Chen et al. 2016; Sun et al. 2019; Zhong et al. 2019). 
However, the related budget of the kinetic energy with respect to KD and KR in WSTR remains unknown. The present paper deals with the budgets of rotational and divergent kinetic energy for a limited area in the warm sector with a focus on the lower troposphere. The detailed contributions of divergent and rotational wind components toward the kinetic energy balance of a specific severe WSTR case are examined. The data sets and methodology are given in Sect. 2. The comprehensive results of budgets of kinetic energy and associated characteristics are given in Sect. 3. A summary and conclusions are given in Sect. 4.

\section{Data and methodology}

\subsection{Data and case overview}

In this study, the budgets of the KD and KR of a record-breaking rainstorm over Guangzhou on 7 May 2017 are examined. The extreme precipitation caused historical maximum of $382.6 \mathrm{~mm}$ accumulated rainfall in $3 \mathrm{~h}$ in the early morning atmosphere (Hoffmann et al. 2019). The horizontal resolution of the data set is $25 \mathrm{~km}$ on 27 isobaric surface levels from the surface up to $100 \mathrm{hPa}$ with hourly temporal intervals.

\subsection{Methods}

Kinetic energy budget equations for KR and KD have been given for a limited area (Buechler and Fuelberg 1986; Zhong 2011). According to Helmholtz's theorem, the horizontal wind can be expressed as the sum of the divergent wind component $\left(\boldsymbol{V}_{\boldsymbol{D}}\right)$ and rotational wind component $\left(\boldsymbol{V}_{R}\right)$

$\boldsymbol{V}=\boldsymbol{V}_{R}+\boldsymbol{V}_{\boldsymbol{D}}$

The kinetic energy per unit mass $(k)$ can be written as

$k=\frac{1}{2} \boldsymbol{V} \cdot \boldsymbol{V}=\boldsymbol{k}_{\boldsymbol{D}}+\boldsymbol{k}_{\boldsymbol{R}}+\boldsymbol{V}_{\boldsymbol{R}} \cdot \boldsymbol{V}_{\boldsymbol{D}}$

The mainly contribution-terms of KD and KR budget equation for a limited volume in isobaric coordinates in this study are given by

$\overline{\frac{\partial K}{\partial t}=\iint-V_{R} \cdot \nabla \emptyset+\iint-V_{D} \cdot \nabla \emptyset+\iint-\nabla \cdot k V_{R}+\iint}-\nabla \cdot k V_{D}+\iint-\frac{\partial \omega k}{\partial p}+D$

KT

(KA)

(KB)

(KC)

(KD1)

(KE1)

$\frac{\partial K D}{\partial t}=\iint-V_{D} \cdot \frac{\partial V_{R}}{\partial t}+\iint-\omega V_{R} \cdot \frac{\partial V_{D}}{\partial p}+\iint-V_{D} \cdot \nabla \emptyset+\iint-\nabla \cdot k V_{D}+\iint-\frac{\partial \omega k}{\partial p}+\mathrm{DD}$

$\begin{array}{lllll}\mathrm{KDT} & (\mathrm{KDA}) & (\mathrm{KDB}) & (\mathrm{KDC}) & (\mathrm{KDD})\end{array}$

$\frac{\partial \mathrm{KR}}{\partial t}=\iint-V_{R} \cdot \frac{\partial V_{D}}{\partial t}+\iint-\omega V_{R} \cdot \frac{\partial V_{D}}{\partial p}+\iint-V_{R} v \nabla \emptyset+\iint-\nabla \cdot k V_{R}+\mathrm{DR}$

KRT

(KRA)

(KDB)

(KRC)

(KRD)

over Xintang Town of Guangzhou (Fig. 1; Wu et al. 2020; Zhong and Chen 2020). The fifth generation of atmospheric reanalysis (ERA5) from the European Centre for MediumRange Weather Forecasts (ECMWF) is used to examine the kinetic energy budgets. Systematic evaluations showed that ERA5 performs a reliable representation of the atmospheric characteristics, including wind distributions (Olauson 2018) and low-level jet characteristics (Kalverla et al. 2019), as well as a fine representation of convective updrafts, gravity waves, tropical cyclones, and other multiscale features of the where $K$ is the kinetic energy. $V_{R}$ and $V_{D}$ are the rotational and divergent wind components, respectively. $\emptyset$ is the geopotential height, and $\omega$ is the vertical velocity. $D, D D$, and $D R$ are residual dissipation terms representing frictional processes as well as transfers of energy between resolvable and unresolvable scales of motion. In Eq. (3), KA and KB are the kinetic energy generations by barotropical and baroclinic processes due to cross-contour flow, respectively (Chen and Wiin-Nielsen 1976). KC and KD1 represent horizontal flux divergence of total kinetic energy, and KE1 denotes vertical 
flux divergence of total kinetic energy. In Eqs. (4) and (5), KDA and KRA represent interactions between KD and KR. KDA denotes the conversions of KD and KR. KDC and KRC represent energy-generation terms as shown in Eq. (1), as well as the terms of KDD and KRD are of representation the horizontal flux divergence of total kinetic energy by $V_{R}$ and $V_{D}$. Finally, $\mathrm{KDE}$ is the vertical flux divergence of $\mathrm{KD}$.

\section{Results}

\subsection{Synoptic conditions}

Low-level jets have been recognized as one of the main triggering systems of the torrential rains in the warmsector over South China (Chen et al. 2016; Du and Chen 2018; Zhang and Meng 2019). Previous studies showed that the extreme precipitation on 7 May 2017 over Guangzhou was mainly caused by the combined effects of urban heat island and the southerly winds as well as the unique topography (Wu et al. 2019; Zhong et al. 2020). To examine the synoptic conditions, Fig. 2 gives the low-level wind fields before the occurrence and during the occurrence of the WSTR. It can be seen that strong northeasterly wind was continuously located over the northeast of SCS

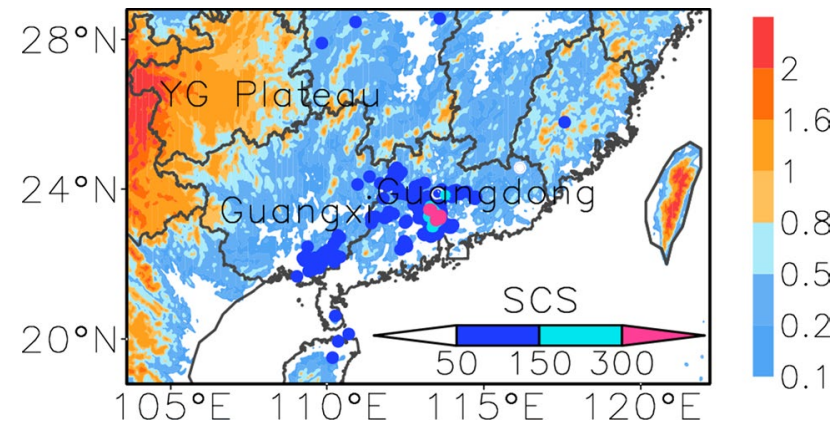

Fig. 1 Topographic distribution over South China (shaded; units: km) and 24-h rainfall at 1200 UTC 07 May (dots; units: mm)

during this extreme precipitation, and there was a relatively high wind-speed tongue stretching into the Pearl River Delta (PRD) regions. For the wind evolution at $850 \mathrm{hPa}$, it showed strong increases of the southerly wind over Guangxi and west of Guangdong.

Note that these two high wind-speed zones were closely linked to the double LLJs in the warm-sector ( $\mathrm{Du}$ and Chen 2018), it is important to investigate its kinetic energy budget over South China. Figures 3 and 4 give the comparisons between the divergent and rotational wind components, as well as the comparisons of the stream function
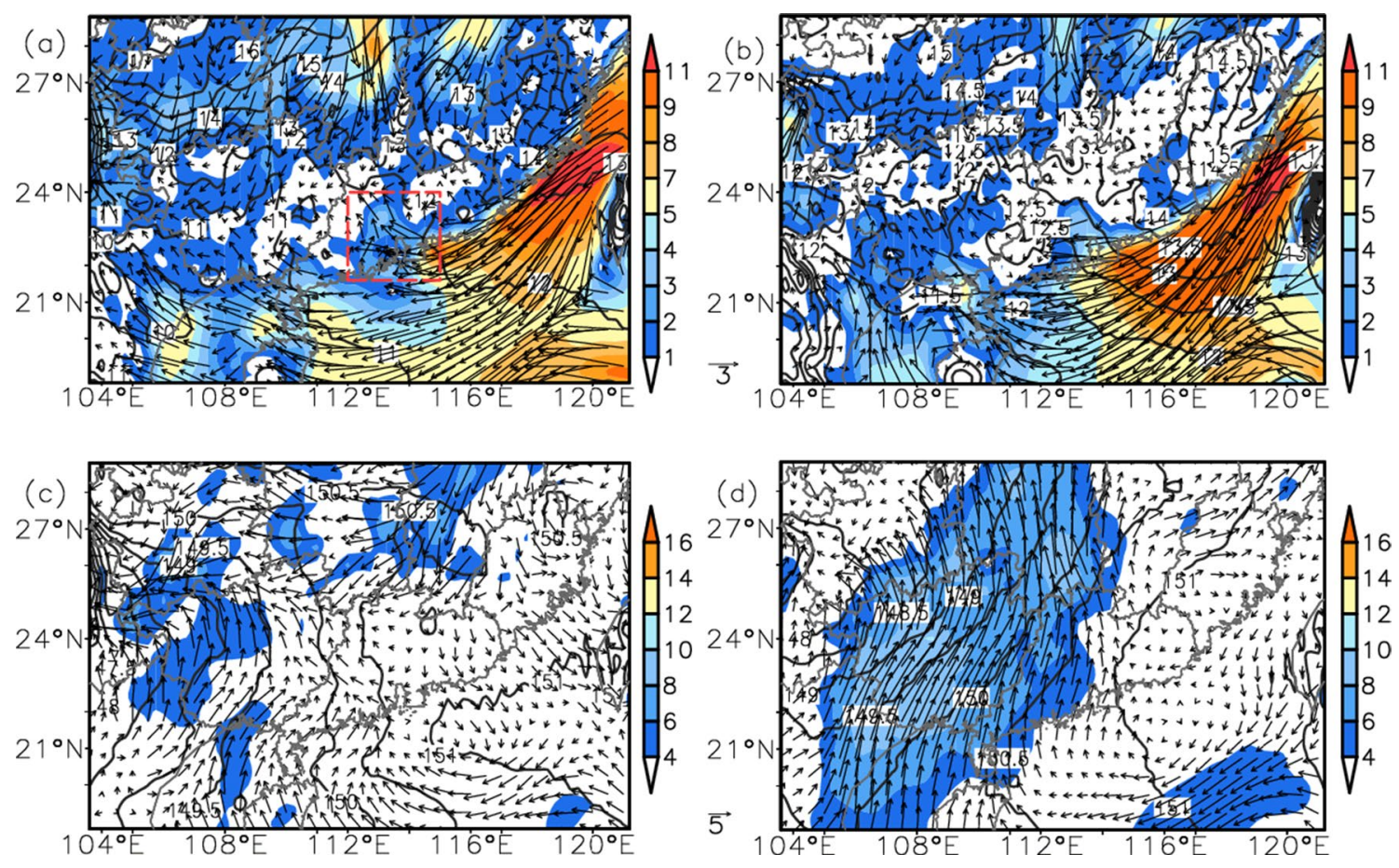

Fig. 2 Horizontal wind over South China (shaded, $\mathrm{m} \mathrm{s}^{-1}$ ) and horizontal geopotential height (contours, $10 \mathrm{gpm}$ ) at (a, b) $1000 \mathrm{hPa}$ and (c, d) $850 \mathrm{hPa}$ of the ERA5 analysis data at (a, c) 1200 UTC 06 May

and (b, d) 0000 UTC 07 May 2017, the red frame in (a) denotes the focus area of the PRD regions 

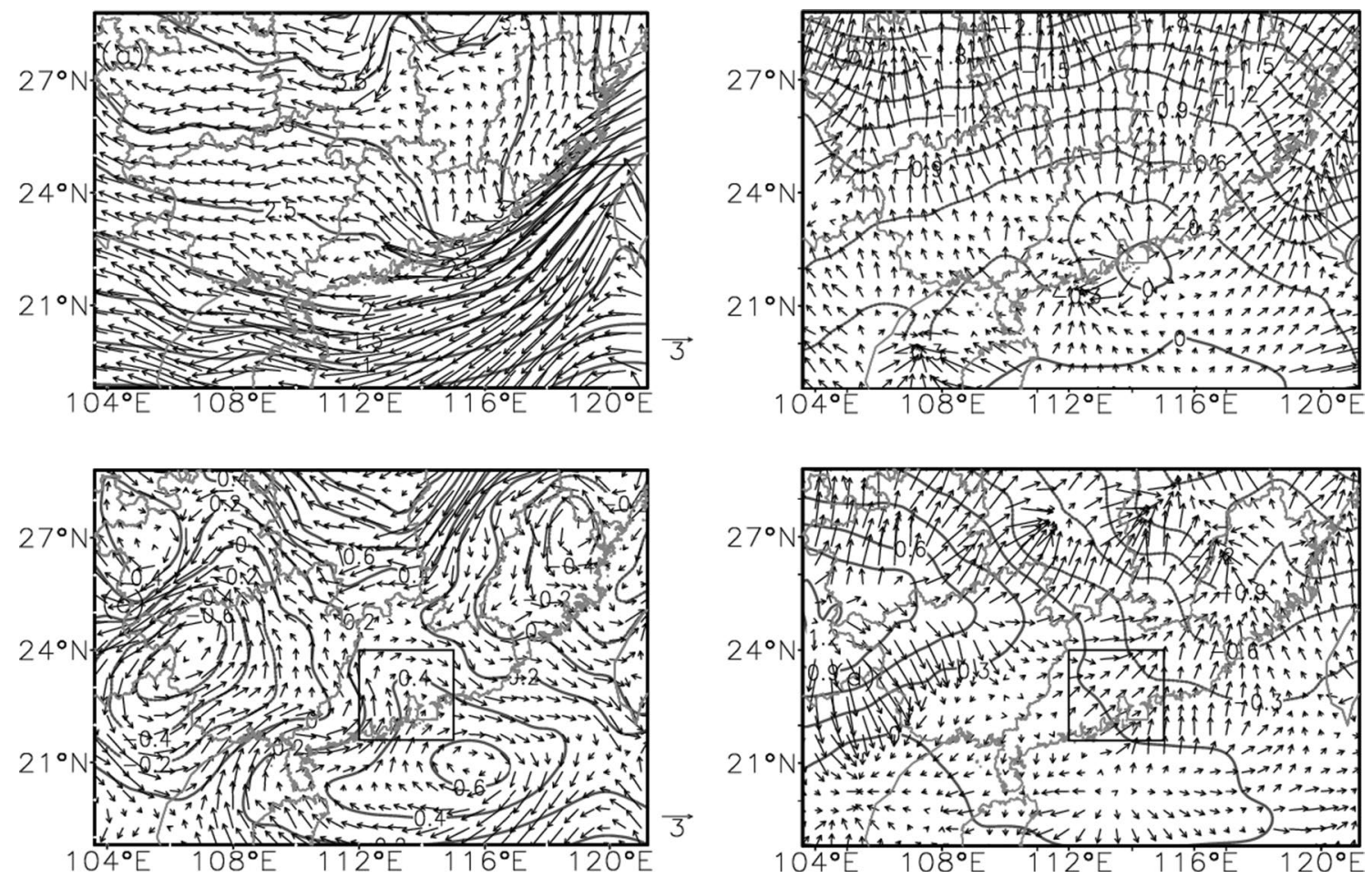

Fig. 3 Horizontal (a, c) rotational wind component and stream function (contour, units: $10^{7} \mathrm{~m}^{2} \mathrm{~s}^{-1}$ ), and (b, d) divergent wind component and velocity potential (contour, units: $10^{7} \mathrm{~m}^{2} \mathrm{~s}^{-1}$ ) over South China at

(a, b) $1000 \mathrm{hPa}$ and (c, d) $850 \mathrm{hPa}$ on 1200 UTC 06 May 2017, the black frame in $(\mathbf{c}, \mathbf{d})$ denotes the domain of averaged-area in Figs. 8 and 9
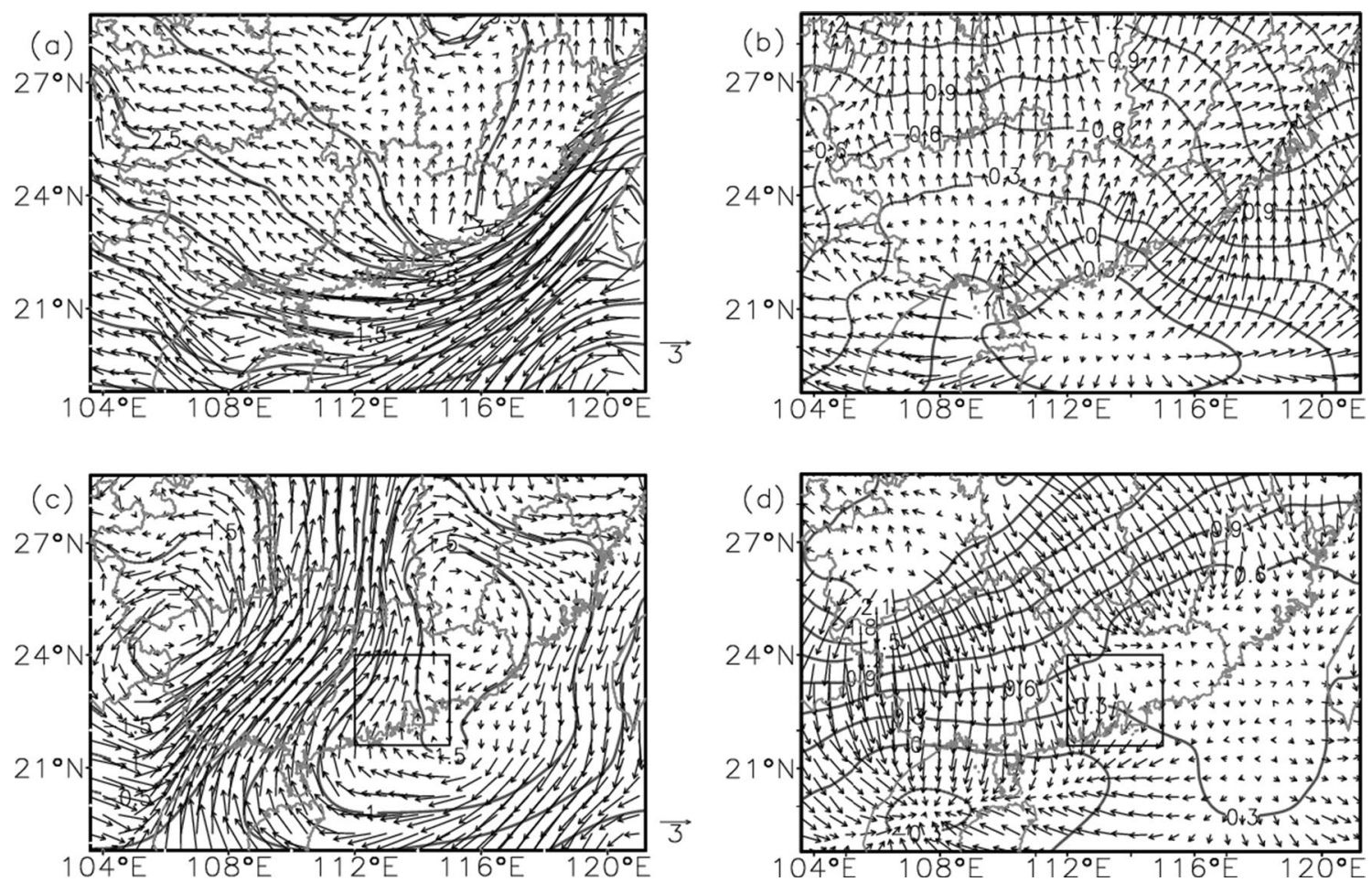

Fig. 4 Same as Fig. 3, but at 0000 UTC 07 May 2017 

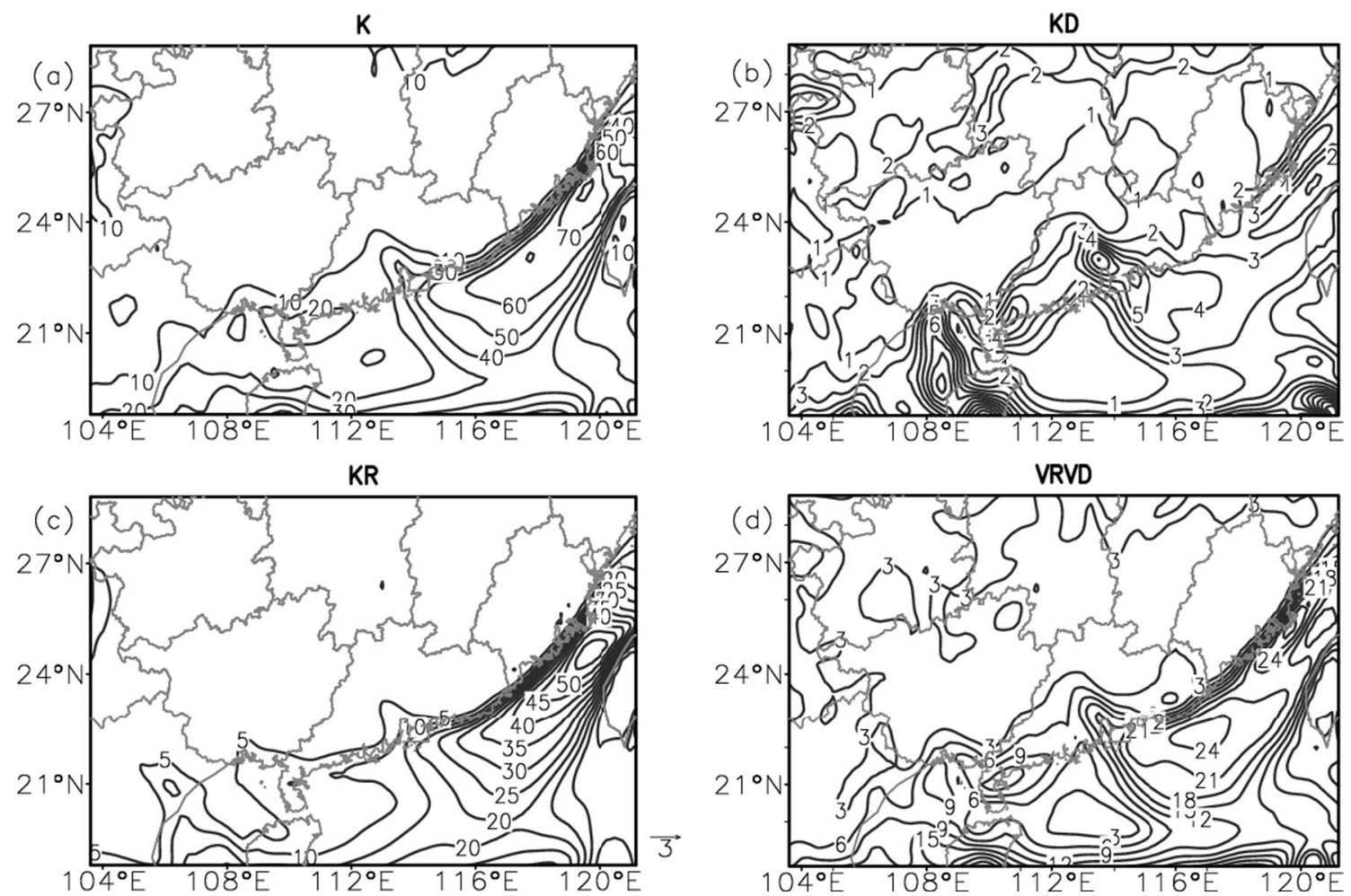

Fig. 5 Horizontal kinetic energy of a K, b KD, c KR and d VRVD over South China (contour, units: $10^{5} \mathrm{~J} \mathrm{~m}^{-2}$ ) at $1000 \mathrm{hPa}$ on $0000 \mathrm{UTC} 07$ May 2017
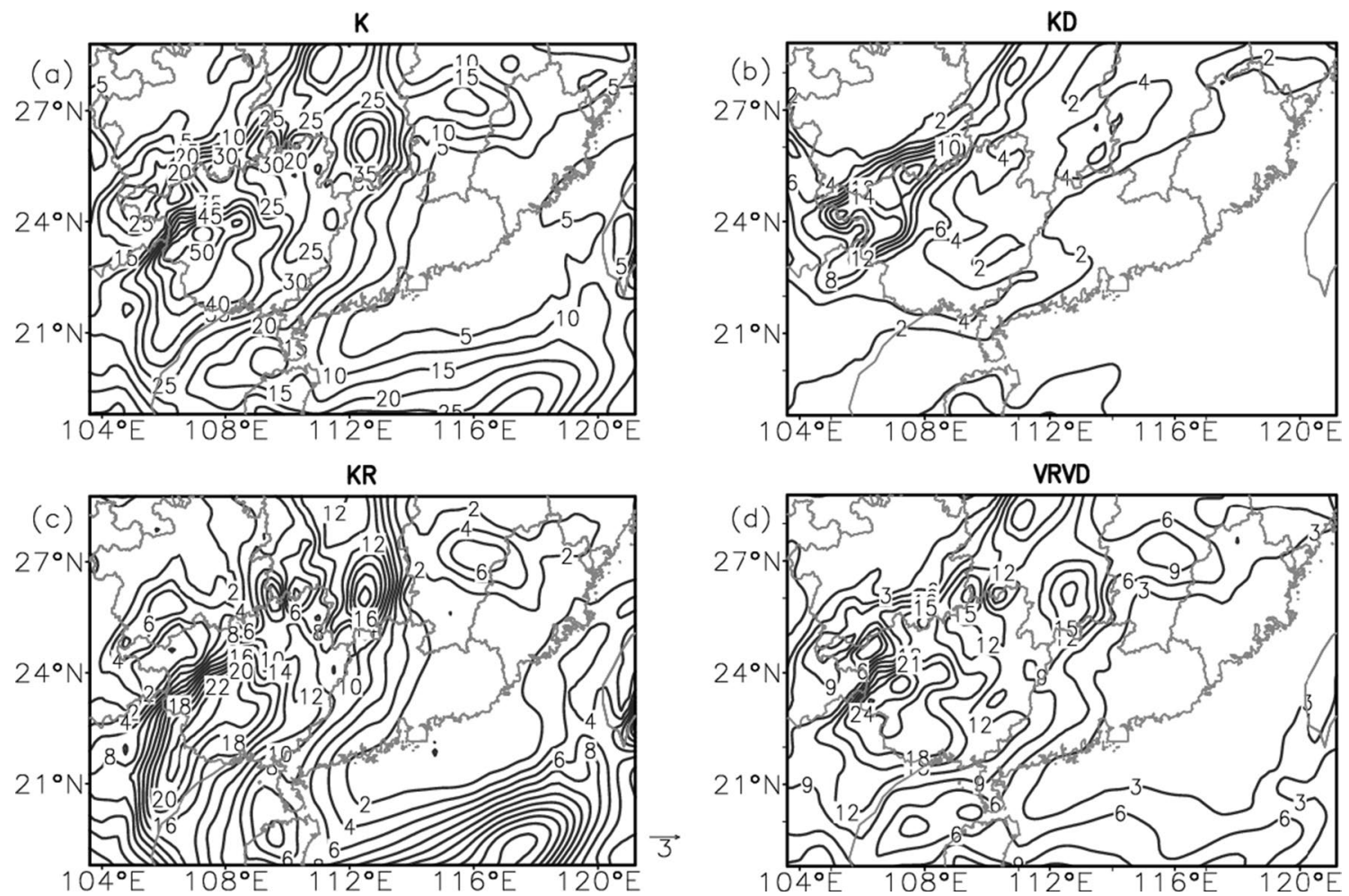

Fig. 6 Same as Fig. 5, but at $850 \mathrm{hPa}$ 
and velocity potential over south China. It can be seen that the rotational wind was generally stronger than the divergent wind, especially over the northeast of the SCS. The velocity potential exhibited generally a low-value center over south China, and the divergent wind showed a generally divergence-center at $1000 \mathrm{hPa}$ over the SCS. Further, the rotational wind showed a generally cyclonic center over southeast of the YG Plateau and an anti-cyclonic center over the north of the SCS at $850 \mathrm{hPa}$, as well as a divergence-center over the east of the YG Plateau.

It should be noted that the divergent wind over the SCS at $1000 \mathrm{hPa}$ and the rotational wind over southeast of the YG Plateau at $850 \mathrm{hPa}$ were continuously existed during this extreme precipitation. In addition, the intensity of the divergence wind over the east of the YG plateau and north of the SCS at $850 \mathrm{hPa}$ exhibited an increasing tendency during the occurrence of the torrential rain. Therefore, the remainder of this paper is devoted to the analysis of such variations of the divergent and rotational wind and the related kinetic energy budgets.

\subsection{Distributional characteristics of the kinetic energy}

The budgets of the kinetic energy in the lower troposphere are examined in the present study. As shown in Fig. 5, the main contribution-terms of kinetic energy over the South China Sea (SCS) and its adjacent areas were the KR and VRVD (the third term on the right-hand-side of Eq. 2). In particular, both KR and VRVD terms showed a high kinetic energy tongue stretching into the PRD regions. Although the $\mathrm{KD}$ exhibited nearly one order of magnitude smaller than $\mathrm{KR}$, it also showed a high-value center over the PRD regions. Nevertheless, for the distribution characteristics over $850 \mathrm{hPa}$ (Fig. 6), the source of the kinetic energy was mainly from northwest Guangdong and Guangxi. The intensity of KD reached the same magnitude as KR, and the PRD regions located on the southeast side of the high kinetic energy belt.

Figure 7 shows the vertical distribution of kinetic energy. It can be seen that the strong kinetic energy was mainly located in the lower troposphere (below $900 \mathrm{hPa}$ ). The
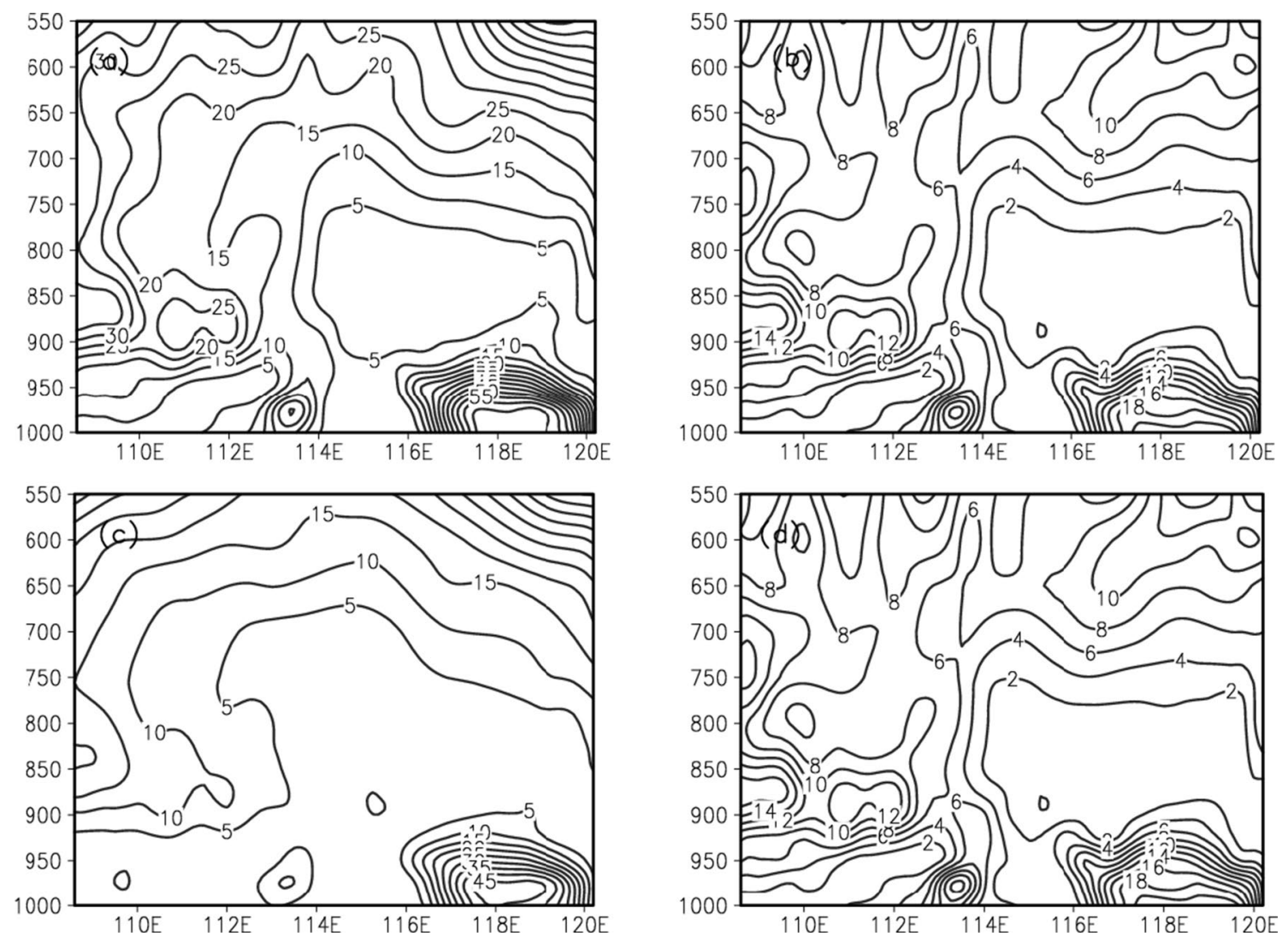

Fig. 7 Vertical cross section of $\mathbf{a} \mathrm{K}, \mathbf{b} \mathrm{KD}, \mathbf{c}$ KR and $\mathbf{d}$ VRVD at $23.16 \mathrm{E}$ (contour, units: $10^{5} \mathrm{~J} \mathrm{~m}^{-2}$ ) at $0000 \mathrm{UTC} 07$ May 2017 

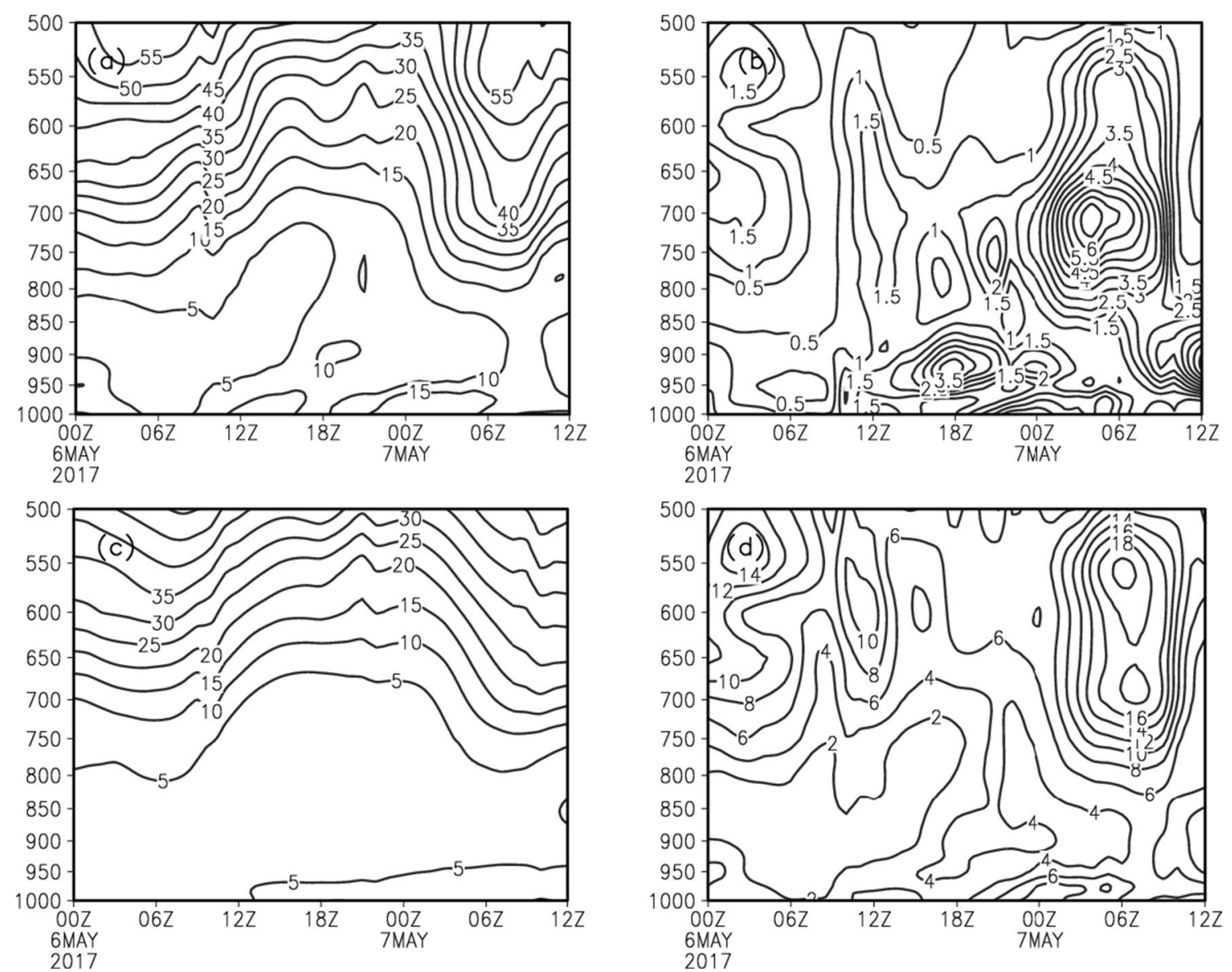

Fig. 8 Pressure-time cross section of mean kinetic energy terms of a K, b KD, $\mathbf{c}$ KR and $\mathbf{d}$ VRVD over the computational regions in Fig. 3c (contour, units: $10^{5} \mathrm{~J} \mathrm{~m}^{-2}$ )

Table 1 Pressure-time average kinetic energy terms (units: $10^{5} \mathrm{~J} \mathrm{~m}^{-2}$ )

\begin{tabular}{lllllll}
\hline Lev & Date & $\boldsymbol{K}$ & $\boldsymbol{K}_{\boldsymbol{R}}$ & $\boldsymbol{K}_{\boldsymbol{D}}$ & $\boldsymbol{V}_{\boldsymbol{R}} \boldsymbol{V}_{\boldsymbol{D}}$ & $\boldsymbol{K}_{\boldsymbol{D}} / \boldsymbol{K}$ \\
\hline 1000 & $06 / 12$ & 11.18 & 4.43 & 1.86 & 4.89 & $16.6 \%$ \\
& $07 / 00$ & 19.03 & 6.73 & 3.47 & 8.83 & $18.2 \%$ \\
850 & $06 / 12$ & 3.75 & 0.85 & 1.12 & 1.78 & $29.9 \%$ \\
& $07 / 00$ & 7.52 & 2.85 & 1.25 & 3.42 & $16.6 \%$ \\
700 & $06 / 12$ & 13.95 & 5.97 & 1.75 & 6.23 & $12.5 \%$ \\
& $07 / 00$ & 11.44 & 3.18 & 2.65 & 5.62 & $23.1 \%$ \\
\hline
\end{tabular}

To quantify the kinetic energy terms of the rotational and divergent wind components, grid-point values of the kinetic energy were averaged in its vicinity (Fig. 8). Time variations of the kinetic energy showed that the KR and VRVD term had a slightly increasing tendency during the whole process of the torrential rains. However, the general kinetic energy and KD showed a significant increasing tendency during the occurrence of the torrential rains. For example, on 1200 

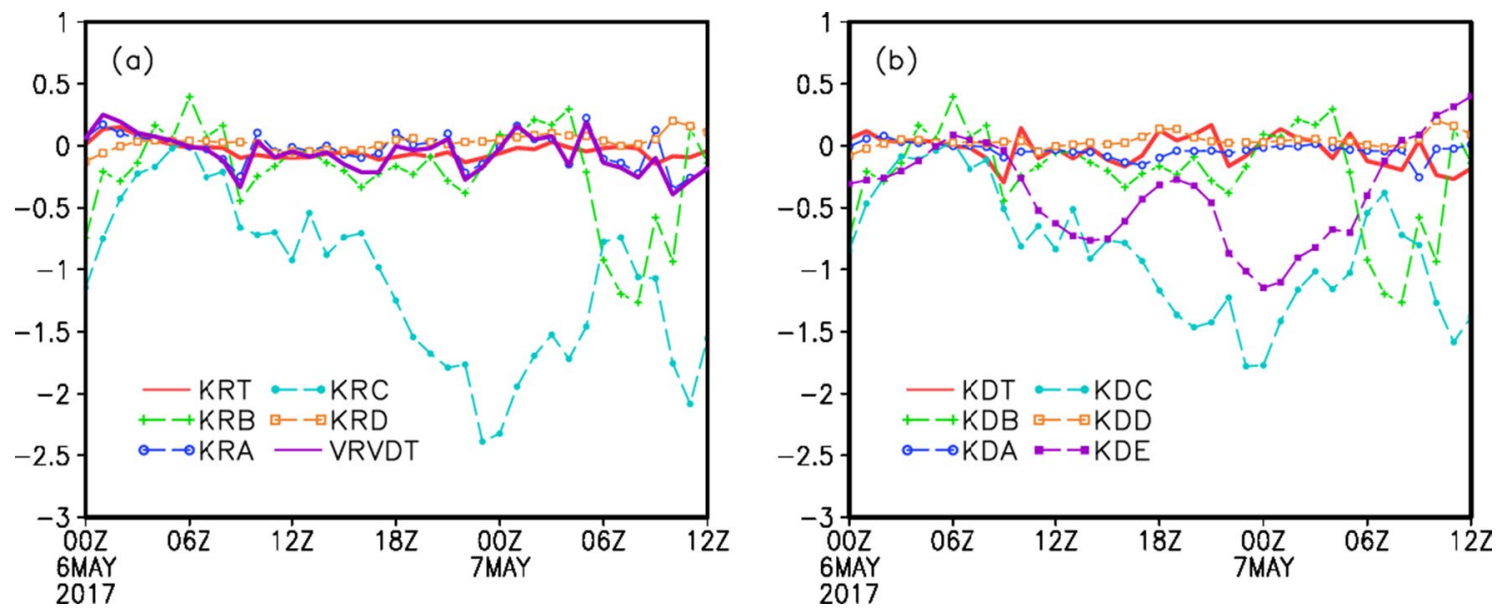

Fig. 9 Time variations of mean budget of $\mathbf{a} \mathrm{KR}$ and $\mathbf{b} \mathrm{KD}$ integrated between the surface and $850 \mathrm{hPa}$ over the computational regions in Fig. $3 \mathrm{c}$ (units: $\mathrm{W} \mathrm{m}^{-2}$ )
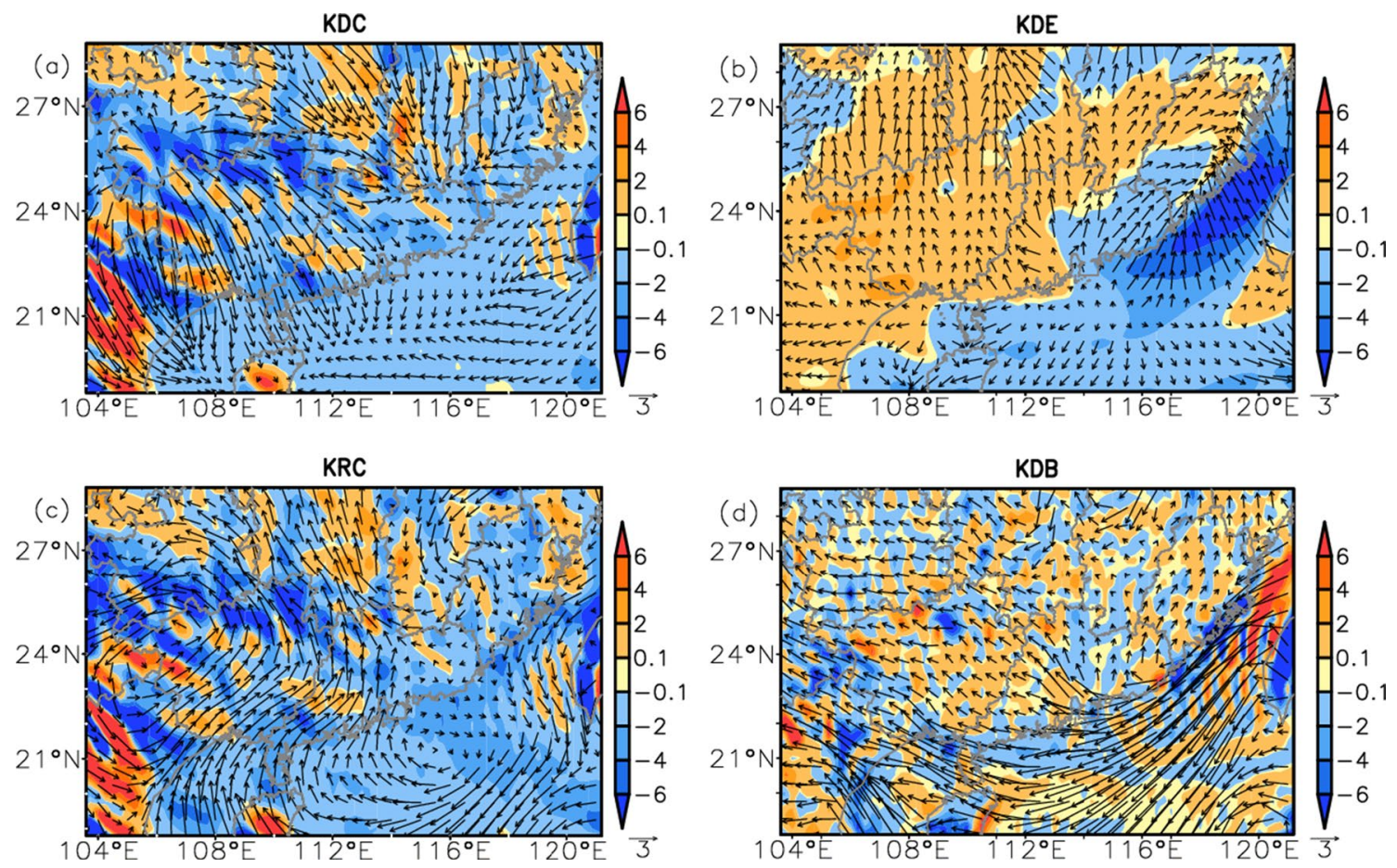

Fig. 10 Horizontal divergent wind and kinetic energy budget terms of a $\mathrm{KDC}$ and $\mathbf{b} \mathrm{KDE}$, and rotational wind and kinetic energy budget terms of $\mathbf{c}$ KRC and $\mathbf{d}$ KDB over South China (shaded, units: $\mathrm{W} \mathrm{m}^{-2}$ )

UTC 6 May, the kinetic energies at $1000 \mathrm{hPa}$ and $850 \mathrm{hPa}$ were $11.18 \times 10^{5} \mathrm{~J} \mathrm{~m}^{-2}$ and $3.75 \times 10^{5} \mathrm{~J} \mathrm{~m}^{-2}$ (Table 1 ), respectively. While on 0000 UTC 7 May, the kinetic energy at $1000 \mathrm{hPa}$ and $850 \mathrm{hPa}$ reached $19.03 \times 10^{5} \mathrm{~J} \mathrm{~m}^{-2}$ and $7.52 \times 10^{5} \mathrm{~J} \mathrm{~m}^{-2}$, respectively. For the $\mathrm{KD}$, the increase mainly occurred at $1000 \mathrm{hPa}$, and for the KR and VRVD, its increases mainly occurred below $850 \mathrm{hPa}$. The kinetic at 0000 UTC 07 May 2017. The kinetic energy budget terms were integrated between the surface and $850 \mathrm{hPa}$

energy at $700 \mathrm{hPa}$ exhibited a slight decrease from 1200 UTC 6 May to 0000 UTC 7 May.

\subsection{Budget of the kinetic energy}

To reveal the specific budget by each term of the KD and KR, Fig. 9 gives the time variations of the main 

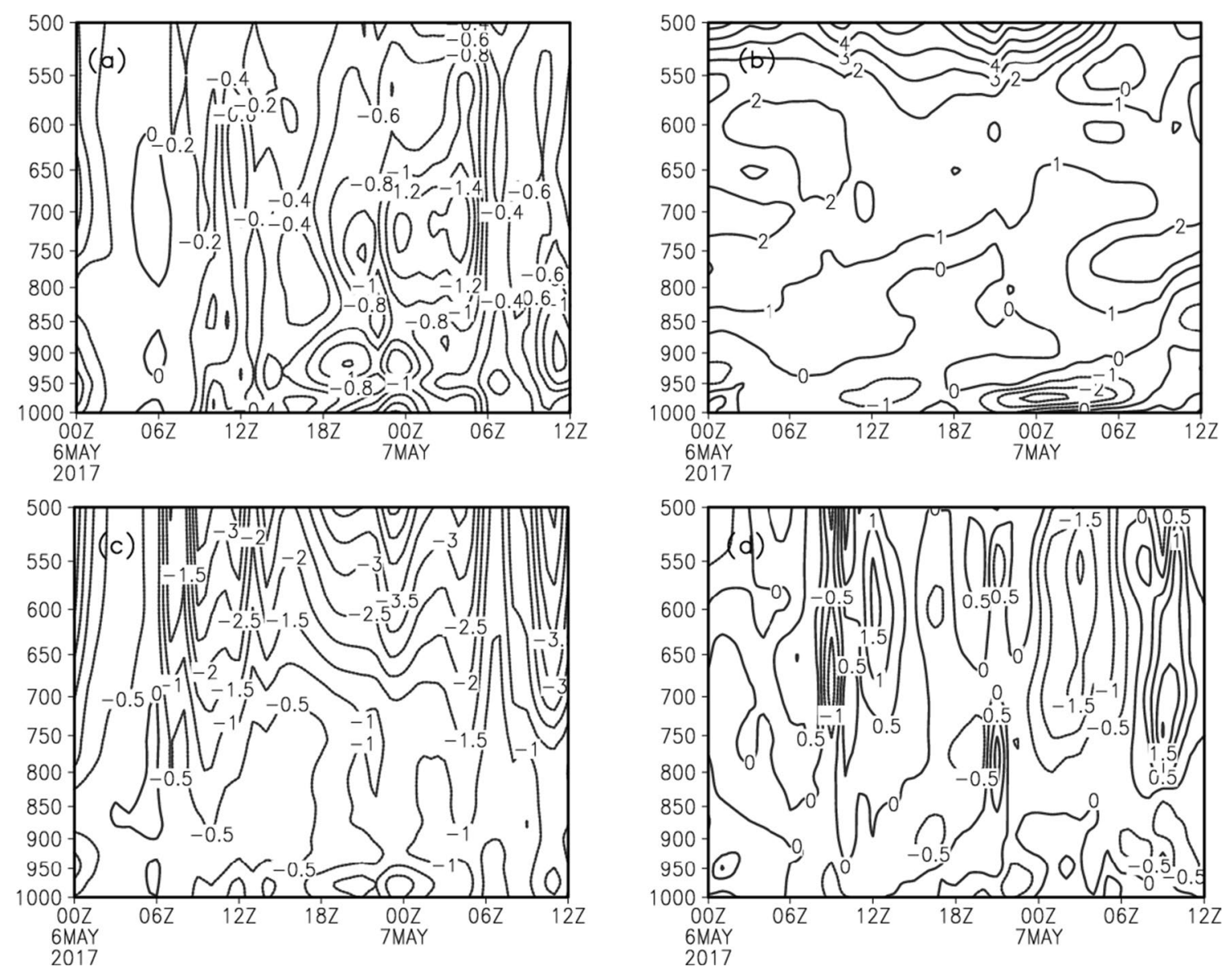

Fig. 11 Pressure-time cross section of area-averaged kinetic energy budget terms of a KDC, b KDE, $\mathbf{c}$ KRC and d KT (units: $10^{2} \mathrm{~J} \cdot \mathrm{m}^{-2} \mathrm{~s}^{-1}$ )
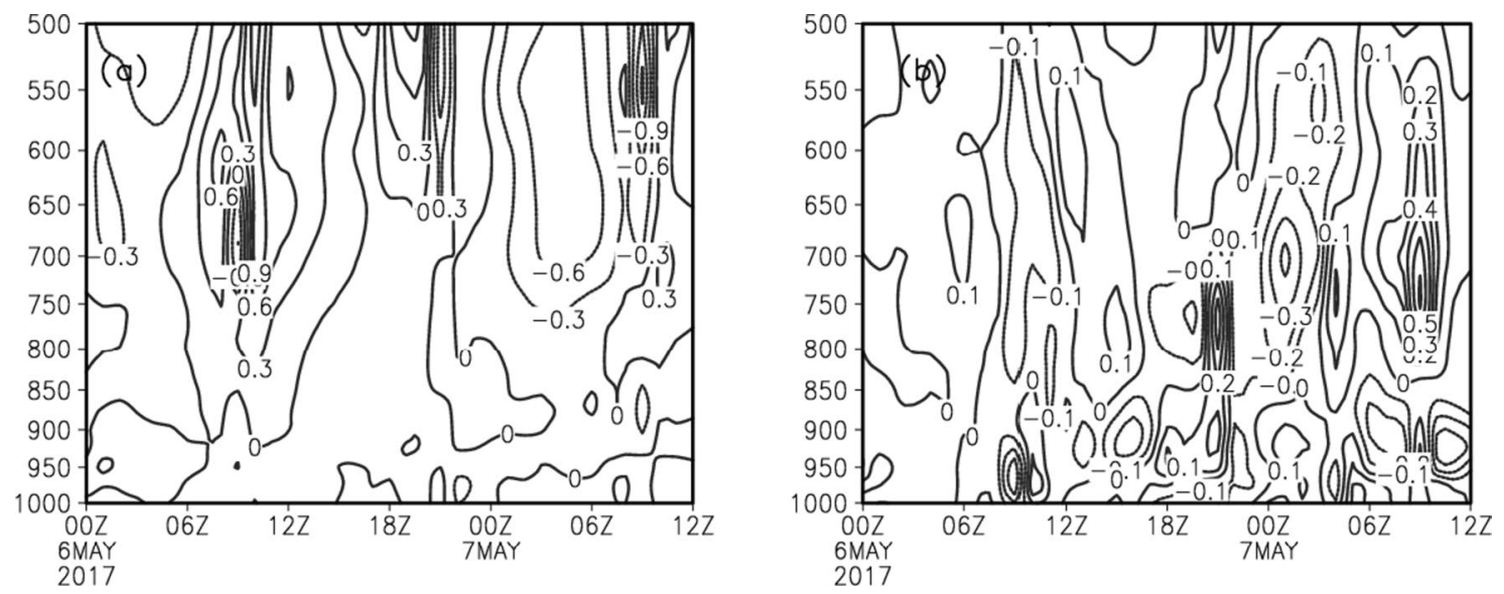

Fig. 12 Same as Fig. 11, but for $\mathbf{a}$ KRT and $\mathbf{b}$ KDT

contribution-terms in Eqs. (4) and (5). It can be seen that the main contribution-terms of KR were the KRC and $\mathrm{KDB}$, especially the term KRC, which represents the KR consumption by barotropical and baroclinic processes due to cross-contour flow. The KRC mainly exhibited a growing consumption of KR before the occurrence of the torrential rains. For the KD, the main contribution-terms of $\mathrm{KD}$ were $\mathrm{KDC}, \mathrm{KDB}$, as well as the vertical flux divergence-term of KDE. 
The horizontal distribution of the contribution-terms of KD budgets showed that the northwest outflow of the divergent wind from the divergence-center over the east of the YG plateau was the main source of the KDC (Fig. 10). Further, the southwest rotational wind from the cyclonic center over the southeast of the YG plateau was the main source of KRC. In addition, the southerly divergent wind and northeast rotational wind from the northeast of SCS contributed to the main variations of the $\mathrm{KDE}$ and $\mathrm{KDB}$.

Time variations of the kinetic energy budget showed that the $\mathrm{KDC}$ and $\mathrm{KRC}$ as well as KDE over the PRD regions exhibited decreasing tendencies during the occurrence of the torrential rains (Fig. 11). The higher tendencies of KDC were mainly located in the lower levels and the KRC was mainly located in the upper levels. The KDE was increased with height, which the negative tendencies were located mainly below $900 \mathrm{hPa}$. The budgets of the kinetic energy showed that strong tendencies were mainly located over the higher levels. However, for the budget of KD, it exhibited relatively stronger variations than KR below $800 \mathrm{hPa}$, while the KR above $800 \mathrm{hPa}$ exhibited relatively stronger variations than KD (Fig. 12). In particular, the KD showed a general increasing tendency between 1000 and $700 \mathrm{hPa}$ during the occurrence-time of the torrential rains on 2100 UTC 6 May. It is interesting to note that the increasing phase of low-level KD corresponded to the increasing phase of high-level KR. As shown in Fig. 11, the main contribution-term of KDC was located in the lower troposphere, and the main contribution-term of $\mathrm{KRC}$ was located in the higher troposphere.

\section{Conclusion}

This paper has examined the relative contributions of divergent and rotational wind components to the kinetic energy budget during a record-breaking rainstorm over South China. The synoptic conditions of the low-level winds as well as the divergent and rotational wind components were examined. Kinetic energy budgets of KR and KD in the lower troposphere were evaluated for the entire computational region of the storm. The main results were as follows:

(1) There was a relatively high wind-speed tongue stretching into the PRD regions from the northeast of SCS at $1000 \mathrm{hPa}$ during this extreme precipitation. It showed strong increases in the southerly wind over Guangxi and west of Guangdong at $850 \mathrm{hPa}$. The rotational wind component was generally stronger than the divergent wind, especially over the northeast of SCS. The velocity potential exhibited generally a low-value center over south China, and the divergent wind component showed a generally divergence-center at $1000 \mathrm{hPa}$ over the SCS. The rotational wind showed a generally cyclonic center over southeast of the YG Plateau and an anti-cyclonic center over the north of the SCS at $850 \mathrm{hPa}$, as well as a divergence-center over the east of the YG Plateau.

(2) The budgets of the kinetic energy in the lower troposphere show that the KD comprised a relatively small proportion of total kinetic energy. The main contribution-terms of kinetic energy were the KR and VRVD. Both KR and VRVD terms showed a high kinetic energy tongue stretching into the PRD regions, as well as a high-value center of KD over the PRD regions. The stratification above $900 \mathrm{hPa}$ exhibited a generally low-value kinetic energy center. The PRD regions were located between the western stretching tongue of high kinetic energy from SCS and the eastern stretching belt of kinetic energy from the west of Guangdong.

(3) The main contribution-terms of KR and KD were the $\mathrm{KRC}$ and KDC by barotropical and baroclinic processes due to cross-contour flow, as well as the vertical flux divergence-term of KDE. The northwest outflow of the divergent wind from the divergence-center over the east of YG plateau was the main source of the KDC, and the southwest rotational wind from the cyclonic center over the southeast of YG plateau was the main source of KRC. The northeasterly rotational wind from the northeast of SCS contributed to the main variations of KDB.

Acknowledgement This work was jointly supported by the National Key Research and Development Program of China (2018YFC1506901), the Key Research and Development Program of Guangdong (2019B111101002), National Natural Science Foundation of China (41505084) and the Project of Guangzhou Science and Technology (201804020038).

Open Access This article is licensed under a Creative Commons Attribution 4.0 International License, which permits use, sharing, adaptation, distribution and reproduction in any medium or format, as long as you give appropriate credit to the original author(s) and the source, provide a link to the Creative Commons licence, and indicate if changes were made. The images or other third party material in this article are included in the article's Creative Commons licence, unless indicated otherwise in a credit line to the material. If material is not included in the article's Creative Commons licence and your intended use is not permitted by statutory regulation or exceeds the permitted use, you will need to obtain permission directly from the copyright holder. To view a copy of this licence, visit http://creativecommons.org/licenses/by/4.0/.

\section{References}

Blažica V, Žagar N, Strajnar B, Cedilnik J (2013) Rotational and divergent kinetic energy in the mesoscale model ALADIN. Tellus A 65(1):18918 
Buechler DE, Fuelberg HE (1986) Budgets of divergent and rotational kinetic energy during two periods of intense convection. Mon Weather Rev 114(1):95-114

Chen XA, Chen YL (2002) Kinetic energy budgets of the low-level jet during TAMEX IOP 5. J Meteor Soc Japan 80(1):1-19

Chen XC, Zhang FQ, Zhao K (2016) Diurnal variations of the land-sea breeze and its related precipitation over South China. J Atmos Sci 73:4793-4815

Chen TC, Wiin-Nielsen AC (1976) On the kinetic energy of the divergent and nondivergent flow in the atmosphere. Tellus 28(6):486-498

Du Y, Chen GX (2018) Heavy rainfall associated with double low-level jets over southern China. Part I: Ensemble-Based Analysis. Mon Weather Rev 146:3827-3844

Fuelberg HE, Browning PA (1983) Roles of divergent and rotational winds in the kinetic energy balance intense convective activity. Mon Weather Rev 111(11):2176-2193

Fuelberg HE, Buechler DE (1989) Energy analysis of convectively induced wind perturbations. Mon Weather Rev 117(4):745-764

Hoffmann L, Günther G, Li D, Stein O, Wu X, Griessbach S, Wright JS (2019) From ERA-Interim to ERA5: the considerable impact of ECMWF's next-generation reanalysis on Lagrangian transport simulations. Atmos Chem Phys 19:5

Jin S, Feng S, Shen W, Fu S, Jiang L, Sun J (2020) Energetics characteristics accounting for the low-level wind's rapid enhancement associated with an extreme explosive extratropical cyclone over the western North Pacific Ocean. Atmos Ocean Sci Let 1:10

Kalverla PC, Duncan JB Jr, Steeneveld GJ, Holtslag AA (2019) Lowlevel jets over the North Sea based on ERA5 and observations: together they do better. Wind Energy Sci 4(2):193-209

Krishnamurti TN, Ramanathan Y (1982) Sensitivity of the monsoon onset to differential heating. J Atmos Sci 39(6):1290-1306

Li WL, Xia RD, Sun JH, Fu SM, Jiang LZ, Chen BF, Tian FY (2019) Layer-wise formation mechanisms of an entire-troposphere-thick extratropical cyclone that induces a record-breaking catastrophic rainstorm in Beijing. J Geophys Res: Atmos 124(20):10567-10591
Li Y (2007) Conversion of kinetic energy from synoptic scale disturbance to low-frequency fluctuation over the Yangtze River valley in the summers of 1997 and 1999. Adv Atmos Sci 24(4):591-598

Maddox RA, Perkey DJ, Fritsch JM (1981) Evolution of upper tropospheric features during the development of a mesoscale convective complex. J Atmos Sci 38(8):1664-1674

Olauson J (2018) ERA5: The new champion of wind power modelling? Renewable Energy 126:322-331

Sun JH, Zhang YC, Liu RX, Fu SM, Tian FY (2019) A review of research on warm-sector heavy rainfall in China. Adv Atmos Sci 36(12):1299-1307

Waite ML, Snyder C (2009) The mesoscale kinetic energy spectrum of a baroclinic life cycle. J Atmos Sci 66:883-901

Wang Y, Cui X, Li X, Zhang W, Huang Y (2016) Kinetic energy budget during the genesis period of tropical cyclone Durian (2001) in the South China Sea. Mon Weather Rev 144(8):2831-2854

Wu Y, Liu Z, Li D (2020) Improving forecasts of a record-breaking rainstorm in Guangzhou by assimilating every 10-min AHI radiances with WRF 4DVAR. Atmos Res 239:104912

Zhang MR, Meng ZY (2019) Warm-sector heavy rainfall in Southern China and its WRF simulation evaluation: a low-level-jet perspective. Mon Weather Rev 147(12):4461-4480

Zhong SX (2011) Structural features of cold vortex and its formation mechanism of heavy rainfall over Northeast China. Ph.D. Dissertation, Chinese Academy of Meteorological sciences

Zhong SX, Yang S, Guo CY, Chen ZT (2019) Capabilities and limitations of GRAPES simulations of extreme precipitation in the warm sector over a complex orography. J Trop Meteor 25(2):180-191

Zhong SX, Chen ZT (2020) A study on the predict ability of GRAPES model over south China: comparisons by two initialization conditions between ECMWF AND NCEP. J Trop Meteor 26(1):27-34

Publisher's Note Springer Nature remains neutral with regard to jurisdictional claims in published maps and institutional affiliations. 